\title{
A contribuição brasileira para as Operações de Paz das Nações Unidas na virada do século: do envio de tropas à cooperação normativa e doutrinária
}

The Brazilian contribution to United Nations Peace Operations at the turn of the century: from troop contribution to the normative and doctrinal cooperation

Ricardo Oliveira dos Santos ${ }^{1}$

DOI: $10.5752 / P .1809-6182.2019 v 16 . n 1 . p 41$

Recebido em: 24 de junho de 2019

Aceito em: 24 de junho de 2019

\section{Resumo}

Tradicionalmente classificado na categoria de "contribuinte simbólico" de tropas para as Operaçóes de Paz das Naçóes Unidas, o Brasil, recentemente, vem desenvolvendo novas formas de assistência aos esforços coletivos de manutenção da paz e segurança internacional. $O$ artigo analisa as recentes contribuiçóes normativas e doutrinárias brasileiras à organização.

Palavras-chave: Naçóes Unidas; Operaçóes de Paz; Brasil.

\begin{abstract}
Traditionally classified under the "token troop contributors" category to United Nations Peace Operations, Brazil is recently developing new ways to assist the collective efforts to maintain international peace and security. The article analyzes the Brazilian normative and doctrinal contributions to the organization.

Keywords: United Nations, Peace Operations; Brazil.
\end{abstract}

1 Professor de Relaçóes Internacionais, Instituto de Relaçôes Internacionais da Pontifícia Universidade Católica do Rio de Janeiro (PUC-Rio), Rio de Janeiro/Brasil. ORCID: 0000-0001-8788-2103. (DD) 


\section{Introdução}

A participação do Brasil nas Operaçóes de Paz da Organização das Nações Unidas (ONU) é marcada historicamente por momentos específicos de elevado engajamento militar. Diferente de países que tradicionalmente figuram na lista dos maiores fornecedores de tropas, o Estado brasileiro contribui de forma estratégica e seletiva para a manutenção da paz e segurança internacional desde o final da década de 1940. Durante o período que compreende a Guerra Fria (1945-1989), o Brasil, no âmbito das Naçóes Unidas, envolveu-se apenas no Comitê Especial das Nações Unidas para os Balcãs e em outras 5 Operações de Paz: a Primeira Força de Emergência das Nações Unidas, a Operação das Naçóes Unidas no Congo, a Força de Segurança das Nações Unidas para a Nova Guiné, a Missão do Representante Especial do Secretário-Geral para a República Dominicana e a Missão de Observação das Naçôes Unidas para a Índia e Paquistão. Dessas participaçóes, destaca-se o desdobramento de 6.300 oficiais militares no Egito entre 1956-1967. Já nos outros casos mencionados, um total de 195 oficiais cumpriram o papel de observadores militares em suas respectivas operaçóes (HAMANN, 2015).

Face à multidimensionalidade das Operaçôes de Paz no pós-Guerra Fria, "a participação do Brasil (...) ganha mais complexidade logística e operacional" (HAMANN, 2015, p. 12). Cabe destacar que a partir do período em questáo o engajamento se torna plural. Conforme demonstra Eduarda $\mathrm{Ha}$ mann (2015), entre 1948 e 2015, o Brasil desdobrou 46.122 militares e policiais em 50 Operações de Paz, dos quais 39.595 (86\%) foram empregados apenas entre 1990-2015. Outro aspecto importante diz respeito ao componente policial e civil, outrora ausentes, como por exemplo acadêmicos e organizaçóes do terceiro setor, que passam a integrar o espectro de tais operaçôes. No contexto de transformaçóes normativas, quantitativas e qualitativas das Operações de Paz no início da década de 1990, ganha notoriedade a contribuição brasileira para a Missão de Verificação das Naçóes Unidas em Angola com 4.217 oficiais, a Missão das Nações Unidas para a Estabilização do Haiti (MINUSTAH - acrônimo em francês) com 30.869 oficiais e a Força Interina das Nações Unidas no Líbano (UNIFIL - acrônimo em inglês), ainda em curso, com 2.125 oficiais $^{2}$ (HAMANN, 2015).

Em função desses três casos, com particular ênfase para o período imediato de início da MINUSTAH, o Brasil foi classificado como um possível contribuinte em ascensão na virada do século (KENKEL, 2015). Essa interpretação recente se deve ao fato de que o alto envolvimento militar brasileiro a partir de 2004 esteve acompanhado de uma série de iniciativas voltadas para o treinamento e aquiescência aos padrōes de segurança internacional previstos pelas Naçôes Unidas - o que possibilitaria um desdobramento mais constante e menos espaçado; pela crescente contribuiçáo normativa e doutrinária do Brasil ao Departamento de Operaçóes de Paz (DPO - acrônimo em inglês) e em outros fóruns da organizaçáo, como a Comissão de Construção da Paz; e, por fim, de modo não exaustivo, em função da atuação de oficiais generais brasileiros como Force Commanders na própria MINUSTAH e na Missão das Nações Unidas para a República Democrática do Congo (MONUSCO - acrônimo em francês). Esses elementos possibilitariam projetar o Brasil como um relevante ator no campo da segurança internacional (KENKEL, 2015). Entretanto, ao contrário do esperado, a

2 Dados publicados em outubro de 2015. Para uma referência completa sobre o número exato da contribuição brasileira em cada participação nas Operaçôes de Paz das Naçôes Unidas desde 1947 até 2015, ver: HAMMAN, Eduarda. A Força de Uma Trajetória. Rio de Janeiro: Instituto Igarapé, 2015. 
contribuição brasileira decresceu significativamente pós-MINUSTAH (2017-), contrariando as expectativas de inserir o país no rol dos maiores contribuintes de tropas (KENKEL, 2018). Coube às distintas instituiçóes brasileiras envolvidas nas Operaçôes de Paz encontrar caminhos alternativos para estabelecer um novo padrão de cooperação para as Naçóes Unidas. Por essas razóes, o Brasil, de forma descoordenada e descentralizada, e muito dependente da ação individual de oficiais militares, vem desempenhando, durante e após o exercício da MINUSTAH, um papel distinto para os esforços de construção da paz. Internalizando, difundido e ressignificando algumas das normas de intervenção das Nações Unidas, o Brasil ao longo dos últimos anos vem estabelecendo um novo padrão de colaboração para as Operaçóes de Paz da ONU.

No contexto de celebração dos 70 anos desse instrumento multilateral, o objetivo do presente artigo é analisar a recente contribuiçâao brasileira a partir de uma dimensão normativa e doutrinária. Com isso, a presente pesquisa pretende demonstrar em que medida esse esforço denota uma transição da posição do país na arquitetura multilateral de segurança como mero doador de tropas para uma assistência institucional em outros termos. Para alcançar tais objetivos, o estudo discorre sobre como esse movimento foi possível graças a incorporação dos padróes onusianos pelos centros de treinamentos dedicados ao aperfeiçoamento do pessoal militar, policial e civil no Brasil. Para tanto, aponta como o aparato institucional do Centro Conjunto de Operações de Paz do Brasil (CCOPAB) e do Centro de Instrução Almirante Sylvio de Camargo (CIASC) possibilitam a internalização, difusão e ressignificação das normas de intervenção das Naçôes Unidas - fazendo com que o Brasil ocupe um espaço tradicionalmente habitado por Estados do norte global. Por fim, o artigo conclui que, face ao atual contexto de incertezas internas e externas, ambas as instituiçôes deverão continuar a memória institucional dos mantenedores da paz no Brasil.

Diante da perspectiva em tela, a pesquisa não pretende traçar um histórico ou desenvolver uma tipologia das diferentes fases da participaçáo do Brasil nas Operaçôes de Paz das Naçôes Unidas. De igual modo, não tem a intenção de discorrer sobre a importância dos diferentes tipos de treinamentos para as tropas empregadas no terreno. Ao contrário, busca refletir, no contexto posterior ao mais alto engajamento militar brasileiro após a Guerra do Paraguai (1864-1870), qual o papel que o CCOPAB e o CIASC podem oferecer para a continuidade do Brasil como um ator relevante nas questôes de paz e segurança das Naçóes Unidas.

\section{Os primeiros passos rumo à construção de um centro integrado de treinamento para as Operações de Paz no Brasil}

Até 2010 inexistia no Brasil um centro integrado de treinamento das Forças Armadas que orientasse, do ponto de vista tático, operacional e estratégico, o pessoal militar, policial e civil empregado nas Operaçóes de Paz da ONU. Diante do expressivo engajamento brasileiro na MINUSTAH, a partir de 2004, iniciou-se uma revisão dos métodos de preparo, treinamento e adestramento dos peacekeepers brasileiros - outrora instruídos pelos sete diferentes Comandos Militares Regionais do Exército. Ainda na década de 1990, como resposta ao retorno do Brasil às Operaçóes de Paz das Naçóes Unidas, após um intervalo de 22 anos, a 5a Subchefia do Estado-Maior do Exército (EME), responsável pelos Assuntos Especiais Internacionais - órgão de direção central do Comandante do Exército assumiu "as atribuiçóes referentes ao emprego do pessoal junto a um grupo de observadores militares de organismos internacionais" (TEIXEIRA, 2017, 
p. 26). Cabia ao EME, de acordo com o entấo Ministério do Exército, preparar individualmente os observadores militares, staff officers e policiais em missóes individuais. Essas medidas possibilitaram que as capacitaçóes individuais, de oficiais empregados em contingentes ou não, deixassem de ser feitas de maneira ad hoc e passassem a ser mais coordenadas. Ainda em 1996, diante do envolvimento brasileiro com tropas militares em Angola, Moçambique e Timor Leste, por iniciativa do entâo Chefe do EME, General do Exército Delio de Assis Monteiro, criou-se o Estágio de Preparação de Militares do Exército Brasileiro para Missóes de Paz "com o objetivo de habilitar militares da Força Terrestre ao desempenho de missões em Forças de Paz sob a égide de organismos internacionais" (TEIXIERA, 2017, p. 26). Cinco anos depois, o Centro de Preparação e Avaliação para Missões de Paz do Exército Brasileiro foi criado na $1^{\text {a }}$ Subchefia do Comando de Operaçóes Terrestres com o propósito de "orientar o preparo de todos os militares do Exército designados para integrar missóes de paz, desobrigando o EME dessas atribuições" (TEIXEIRA, 2017, p. 26). Já na virada do século, como resposta tardia à Resolução 44/49 da Assembleia Geral da $\mathrm{ONU}^{3}$ (1989), dois pontos de inflexão permitiriam uma maior profissionalização e normatização aos padróes onusianos das tropas brasileiras: o primeiro, fora a criaçáo em 2005 do Centro de Instrução de Operações de Paz (CI Op Paz), e, posteriormente, em 2010, o estabelecimento do Centro Conjunto de Operaçóes de Paz do Brasil (CCOPAB). Ambos os Centros institucionalizaram a prática e disseminaram os procedimentos e normas vigen-

3 A referida resolução intitulada "Revisão Abrangente da Questão das Operações de Paz em Todos os seus Aspectos”, datada de 8 de dezembro de 1989, estimula, entre outros pontos, que os Estados membros das Naçốes Unidas desenvolvam os seus próprios mecanismos de treinamento de tropas empregadas nas Operaçóes de Paz autorizadas pelo Conselho de Segurança (UNITED NATIONS, 1989). tes das Operaçóes das Naçóes Unidas no Brasil (TEIXEIRA, 2017). Ao mesmo tempo elaboraram oportunidades para que as experiências obtidas no terreno pudessem ser convertidas em mecanismos de difusão de expertise no exterior - conforme será apresentado nos próximos parágrafos.

Sendo uma Organização Militar Diretamente Subordinada à $1^{\text {a }}$ Divisão de Exército, o CI Op Paz desenvolveu uma série de Cursos e Estágios seguindo os padrōes previstos pelo Standardized Generic Training Module (SGTM) das Naçôes Unidas (TEIXEIRA, 2017). Centralizando as atividades de ensino e treinamento de outras unidades do Exército voltadas às Operaçóes de Paz, o CI Op Paz gradativamente criou cursos que permitissem a internalização de tais referências, como o Exercício Avançado de Operaçóes de Paz (EAOP), o Estágio de Preparaçáo para o Comandante e o Estado-Maior Combinado (EPCOEM), o Estágio de Preparação para Comandantes de Subunidade e Pelotão (EPCOSUPEL) e o Estágio de Preparação para Missões de Paz (EPMP). Para os civis, o CI Op Paz ofereceu capacitações através do Estágio para Jornalistas e Assessores de Imprensa em Áreas de Conflito (EPJAIAC), o Curso Integrado de Desarmamento, Desmobilização e Reintegração (CIDDR) e o Curso de Salvaguarda e Segurança na Abordagem dos Trabalhos em Campo (SSAFE). Uma questão digna de nota é a de que antes mesmo da criação do CCOPAB, o DPO (na época Departamento de Operaçóes de Paz - DPKO, acrônimo em inglês) premiou o CI Op Paz com o Certificado de Reconhecimento pelo seu aprimoramento nos Exercícios Básico e Avançado de Operaçóes de Paz e pelo cumprimento das exigências das Naçôes Unidas pelo treinamento pré-desdobramento (TEIXEIRA, p. 28). Um ano antes, o mesmo DPO, em parceria com o CI Op Paz, conduziu o curso de Senior Mission Leadership Course (SML) "para 24 Oficiais Generais, policiais e civis de vários países, 
Figura 1 - Organograma do Centro Conjunto de Operações de Paz do Brasil

\section{COMANDANTE}

\section{SCmt \\ DP DS DPC DALog DCS DCTI DET DTI DD DAvI}

Fonte: CENTRO CONNJUNTO DE OPERAÇÓES DE PAZ DO BRASIL, 2019a, s/p.

candidatos a líderes sêniores de missões de paz" (TEIXEIRA, 2017, p. 29). Iniciava-se, portanto, um processo gradativo de aquiescência às normas globais de intervenção onusianas.

Cinco anos depois, em 15 de junho de 2010, o Ministério da Defesa (MD), alinhado às Estratégias e Políticas Nacionais de Defesa de 20084, organiza, a partir da portaria número 952-MD, em substituição ao CI Op Paz, o CCOPAB - que conserva, por um lado, a mesma lógica de subordinação hierárquica no plano do Exército Brasileiro5, mas que, por outro lado, inova ao vincular o CCOPAB ao MD (MARCONDES; SÍMAN; OLIVEIRA, 2019). Objetivando facilitar a interoperabilidade das Forças Armadas no Brasil de modo geral e facilitar o diálogo das Forças no contexto de uma Operação de Paz das Nações Unidas, de modo específico, o CCOPAB, conforme o próprio nome destaca, se torna um centro conjunto e instituição reconhecida pelas Naçóes Unidas para o treinamento e pre-

4 A criação do CCOPAB está alinhada ao objetivo de "promover o incremento do adestramento e da participação das Forças Armadas em operaçóes internacionais em apoio à política exterior, com ênfase nas operaçôes de paz e açôes humanitárias, integrando Forças da Organização das Naçôes Unidas (ONU) ou de organismos multilaterais da região". (GOVERNO FEDERAL DO BRASIL, 2012, p.136).

5 O Centro Conjunto de Operações de Paz do Brasil tem vinculação direta ao Comando de Operações Terrestres (COTER) "para efeitos de planejamento, orientação e supervisão das atividades de instrução e adestramento, bem como, ao Departamento de Educação e Cultura para efeito de orientação técnico-pedagógica" (CENTRO CONNJUNTO DE OPERAÇÓES DE PAZ DO BRASIL, 2019b, s/p). paro dos peacekeepers brasileiros (MARCONDES; SÍMAN; OLIVEIRA, 2019). Nesse sentido, a referida instituição propóe-se, desde a sua fundação, tornar-se uma referência na preparação, treinamento e ensino dos padróes normativos e doutrinários no que tange às atividades de manutenção da paz e segurança internacional conduzidas pela ONU.

Conforme o organograma abaixo demonstra, o CCOPAB atualmente conta com 10 Divisóes: Divisão de Pessoal (DP), Divisão de Segurança (DS), Divisão de Planejamento e Coordenação (DPC), Divisão de Administração e Logística (DALog), Divisão de Comunicação Social (DCS), Divisão de Comunicaçôes e Tecnologia da Informaçẫo (DCTI), Divisão de Educação e Treinamento (DET), Divisão de Tradutores e Intérpretes (DTI), Divisão de Doutrina (DD) e Divisão de Avaliação (DAvl). Todas são supervisionadas por um Comandante oriundo do Exército e por um Subcomandante da Marinha e da Aeronáutica que se revezam na posição (CENTRO CONJUNTO DE OPERAÇÓES DE PAZ DO BRASIL, 2019a, s/p).

Para efeitos de delimitação, basta destacar que cabe à DD produzir artigos e desenvolver pesquisas em áreas como gênero, segurança e a implementação do plano Nacional de Açáo de Gênero; além de realizar ponderaçôes acerca da repercussão e verificação da implementação das recomendaçôes elencadas no Relatório "Santos Cruz"; reflexão sobre os desafios relacionados à proteção de civis nas Operaçoóes de Paz com foco na Missão das Nações Unidas na República Centro-Africana (MINUSCA - acrônimo em francês), 
MONUSCO e UNIFIL; monitoramento das urgências elencadas pelo recente Painel Independente de Alto Nível sobre Operaçóes de Paz "HIPPO Report"; avaliaçáo das consequências dos 13 anos da participação brasileira no Haiti e em outras operaçóes vigentes e sua relação com a atual conjuntura de segurança pública no país; observaçóes sobre a atuação brasileira com unidades aéreas em Operações de Paz; estudo sistemático sobre mediação de conflitos armados não convencionais; os desafios da Coordenação Civil-Militar e os Projetos de Impacto Rápido em Operações de Paz no continente africano; e, por fim, não exaustivamente, o estudo sobre a história das Operaçóes de Paz e o seu estado moderno, bem como a importância do Brasil no Conselho de Segurança ${ }^{6}$ (CENTRO CONNJUNTO DE OPERAÇÓES DE PAZ DO BRASIL, 2018, s/p). Diante do exposto, a DD representa o lócus institucional de análise do estado da arte normativo sobre as Operaçôes de Paz, buscando estabelecer caminhos doutrinários possíveis de contribuição, em parceria com outras unidades do Exército e do Estado brasileiro, para os esforços de manutenção da paz e segurança internacional no âmbito das Naçốes Unidas.

6 Além das atividades mencionadas, a DD atua na produção de materiais para análise interna, tais como relatórios sobre o futuro das operaçóes de paz e cenários possíveis, relatando oportunidades e riscos que podem ocorrer no contexto de uma Operação de Paz das Naçôes Unidas em curso, tais como a MINUSCA, MONUSCO e UNIFIL. Além disso, produz-se relatórios de contextos sobre as demais Operaçóes de Paz autorizadas pela organizaçáo. Do ponto de vista dos interesses brasileiros, cabe à esta Divisão avaliar ameaças à geopolítica estratégica brasileira em relação às Operaçóes de Paz da ONU e a de elencar oportunidades para a atuaçáo das Forças de Paz brasileiras. Dentre as atividades previstas em campo, a Divisão de Doutrina assiste e acompanha os cursos e treinamentos do CCOPAB, garantindo que todas essas atividades possam seguir os padróes normativos e doutrinários das Nações Unidas. De igual modo, fornece instruções fora do CCOPAB, como em organizaçôes da Marinha, do próprio Exército ou da Aeronáutica. Por fim, auxilia na organização de eventos nacionais e internacionais sobre a temática das Operaçôes de Paz (CENTRO CONNJUNTO DE OPERAÇÓES DE PAZ DO BRASIL, 2018, s/p).
Outra divisão que merece atenção é a DAvl, responsável por "introduzir, de maneira metodológica, os processos de avaliação e certificação para missôes de paz, estabelecendo parâmetros de desempenho integrados com as diretrizes emanadas de Nova Iorque e, ao mesmo tempo, consoantes com os protocolos do sistema de ensino do Exército" (TEIXEIRA, 2017, p. 30). No caso da Divisão de Cooperação e Planejamento, cabe o desdobramento das Equipes Moveis de Treinamentos (EMTs), instrumento de colaboração previsto pelo CCOPAB em parceria com a $5^{\text {a }}$ Subchefia do EME (TEIXEIRA, 2017). Além dessa responsabilidade, a DCP vem estabelecendo mecanismos de cooperação com diversos Centros de Treinamento, Organizaçóes Internacionais e Estados para expandir a expertise do Brasil no que tange à manutenção e construçáo da paz em sociedades afetadas por conflitos armados. Interessante notar que tanto a DD quanto a DCP vêm estreitando os laços com setores da sociedade civil, como, por exemplo, centros de pesquisa e ensino de excelência, principalmente no contexto da Rede Brasileira de Pesquisa sobre Operaçōes de Paz (REBRAPAZ) ${ }^{7}$.

O CCOPAB, assim como os demais centros de treinamento ao redor do mundo, oferece diversos Cursos e Estágios passíveis de certificação pelo DPO através do Serviço de Treinamento Integrado (ITS acrônimo em inglês). $\mathrm{O}$ documento que normatiza estas certificaçóes é o Standard Operation Procedure: Training Recognition (2009). Cursos e Estágios que não estão previstos no âmbito do ITS, sob a égide do Core Pre-Deployment Training Materials (CPTM) e do Specialized Training Materials (STMs), são reconhecidos com o título de Training Acknowledgement e ainda estáo no processo de normatizaçáo da sua validaçáo. Até maio de 2017, o DPO, em diferentes momentos, certificou o CCOPAB (por um período de 4 anos,

\footnotetext{
7 Para uma referência completa sobre as instituiçóes integrantes da REBRAPAZ, ver: <https://rebrapaz.com/>.
} 


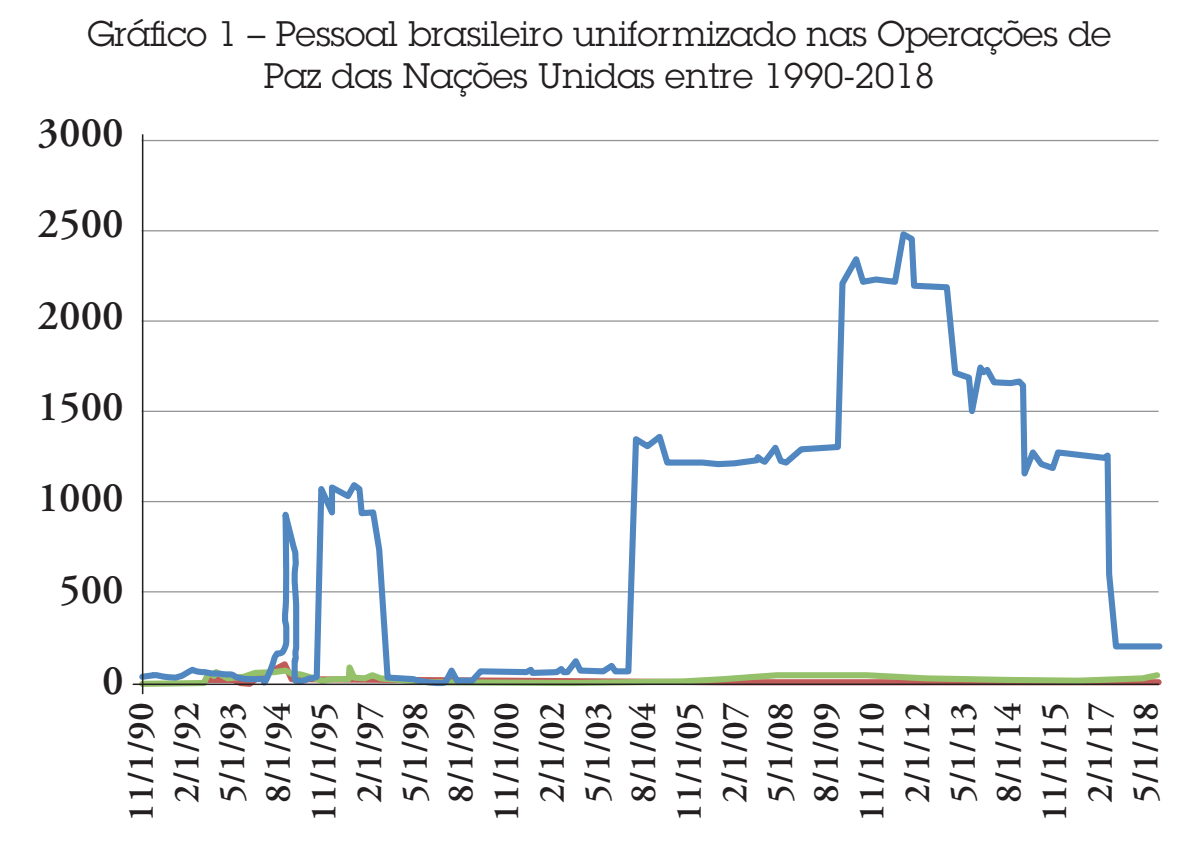

- Tropas - Polícia - Experts

Fonte: KENKEL, 2018, s/p.

renováveis) em três Cursos/Estágios: Preparação de Experts Militares da Missão; Preparação de Comandantes de Organização Militar e Estado Maior; e Oficiais Individuais de Polícia. Os demais Cursos e Estágios que seguem ou não o STM e o CPTM estão em processo de certificação pelo ITS (MARCONDES; SÍMAN; OLIVEIRA, 2019). Comparado ao CI Op Paz, o CCOPAB oferece uma quantidade mais extensa de Cursos e Estágios, todos seguindo os padrōes previstos pela $\mathrm{ONU}^{8}$. Nesse sentido, constata-se que a instituição vem comprometendo-se ao longo dos últimos 9 anos com a aquiescência e difusão, no âm-

8 Os Estágios e Cursos oferecidos atualmente pelo CCOPAB são: o Estágio de Preparação para Missōes de Paz; Estágio de Ação Contra Minas; Estágio de Tradutores e Intérpretes Militares; Estágio de Preparação de Comandantes de Subunidade e Pelotôes; Exercício Avançado de Operaçôes de Paz; Estágio de Preparação de Comandantes e Oficiais de Estado Maior de Organização Militar de Força de Paz; Estágio de Jornalismo e Assessoria de Imprensa em Áreas de Conflito; Estágio de Logística e Reembolso em Operaçôes de Paz; Estágio de Coordenação Civil-Militar; Estágio de Preparação de Civis para Atuação em Ambientes Instáveis (CENTRO CONNJUNTO DE OPERAÇÓES DE PAZ DO BRASIL, 2019 c, s/p). bito dos treinamentos oferecidos para os seus oficiais e de naçôes amigas, das normas e doutrinas de treinamento táticos desenvolvidas pelo DPO das Naçóes Unidas. Desde 2010 o CCOPAB contribui individualmente para uma ampla gama de países ao redor do globo, promovendo o intercâmbio de oficiais brasileiros, como alunos e instrutores, em diversos centros de treinamento, workshops, congressos e demais atividades relacionadas ao universo das Operaçōes de Paz das Naçóes Unidas (TEIXEIRA, 2017).

Ao manter e expandir, em alguns aspectos, o aparato institucional do CI Op Paz, o CCOPAB reivindica para si o papel de principal agente credenciado pelas Nações Unidas em questóes de treinamento e profissionalização de tropas. Cabe ao CCOPAB, mesmo diante da redução drástica de tropas desdobradas no terreno, manter as atividades de ensino e pesquisa. No momento em que a participação das tropas brasileiras decresceu de forma significativa, conforme a figura abaixo apresenta, um dos principais mecanismos encontrados pelo Centro tem sido o de engajar-se cada vez mais na arquitetura de segurança internacional, contribuindo com sua expertise para projetos 
de cooperação e de manutenção da paz e segurança internacional através, principalmente, das EMTs.

Com o avanço institucional obtido a partir de sua criação, o CCOPAB dispóe de uma estrutura que o permite ocupar um espaço nacional e internacional até então inabitado pelo Brasil. Tal status foi consolidado em grande medida graças ao papel desempenhado pelos diferentes Comandantes que já ocuparam tal posição no Centro Conjunto de Operaçôes de Paz do Brasil. Com históricos de participação diferentes no DPO e no sistema da ONU como um todo, cada um, ao seu modo, contribuiu para que o CCOPAB identificasse oportunidades e respondesse à algumas demandas das Naçóes Unidas, principalmente aquelas relacionadas à treinamento e capacitação - enfatizadas por diversos documentos, relatórios e resoluçóes. Cabe destacar, por exemplo, que com a criação do CCOPAB, o Brasil ingressou como membro permanente na Associação Latino-Americana para Operaçôes de Paz (ALCOPAZ - acrônimo em espanhol). De igual modo, permitiu que o Brasil negociasse a realização da Conferência da Associação Internacional de Centros de Treinamento de Operaçóes de Paz (IAPTC - acrônimo em inglês). Em cada uma dessas oportunidades, o Brasil, utilizando-se da sua narrativa pela experiência na MINUSTAH, apresenta-se como um importante global player nos assuntos de segurança internacional, compartilhando suas experiências e particularidades para a construção da paz.

Da mesma forma em que as Naçóes Unidas através de suas regras estabelecem o papel de agência para o CCOPAB, esse, por sua vez, a partir das suas atividades de preparo, ensino e aplicabilidade no terreno abre espaço para uma constante revisão de tais termos. A extensa bibliografia sobre o "jeito brasileiro de fazer operaçóes de paz" aponta, por exemplo, para a flexibilidade, capacidade de negociação e criatividade das tropas brasileiras desdobradas no terreno no que tange ao desenvolvimento de atividades relacionadas à Coordenação Civil Militar e às Ações Cívicos Sociais.
A potencialidade dessa adaptação e flexibilidade dos contingentes brasileiros no terreno leva a uma maior expertise do contingente brasileiro, difundida, por exemplo, através das já mencionadas EMTs. Até o presente momento, países como Angola, Colômbia, Moçambique, Namíbia e, mais recentemente, o México foram os Estados que receberam as EMTs. Dentre as suas funçôes estão a de "apresentar e disseminar o material de treinamento das Naçóes Unidas; dar o apoio ao país anfitriāo na construção de capacidades de recursos humanos para fornecer treinamento para militares, policiais e civis que podem ser desdobrados nas Operaçóes de Paz das Naçóes Unidas; e incrementar a cooperação entre o Brasil e o país anfitrião na área das Operaçóes de Paz" (MARCONDES; SÍMAN; OLIVEIRA, 2019, p. 218, tradução livre). De acordo com a Instrução Normativa No 2/EMCFA/MD, de 17 de junho de 2019, as EMTs do CCOPAB devem se encarregar das seguintes tarefas de cooperação junto às nações amigas apoiadas: "apoio à criação de cursos, desenvolvimento de currículos e técnicas de ensino; treinamento de instrutores; montagem e controle de exercícios no terreno; orientação técnica de treinamento e desenvolvimento de capacidades; e avaliação e certificação de cursos e exercícios do país apoiado.” (BRASIL, 2019). Conforme Danilo Marcondes, Maíra Síman e Ricardo Oliveira destacam, as Equipes Moveis de Treinamento evidenciam como o "novo status encontrado pelo país como um exportador de segurança vem sendo utilizado para ganhar legitimidade no nível regional e internacional"10 (MARCONDES; SÍMAN; OLIVEIRA, 2019, p. 200, tradução livre).

Contando com instrutores oriundos da MINUSTAH, os oficiais da Divisão de Doutrina e Ensino, res-

9 "present and disseminate UN training material; support the host country in the capacity-building of human resources to provide training for military, police and civilians to be deployed in UN peace missions; increase cooperation between Brazil and the host country in the area of peacekeeping"

10 "the country's newly found status as a security exporter has been used to gain legitimacy at the regional and world level". 
ponsáveis pelo planejamento e ensino, no contexto de formação dos peacekeepers brasileiros e de naçóes amigas, estabelecem como referencial normativo, doutrinário e prático além dos documentos já mencionados, uma abordagem que envolve a construçáo da paz de modo alargado, para além da definição do DPO. Dentre essas atividades as mais destacadas seriam aquelas relacionadas à promoção do desenvolvimento no médio e longo prazo, além do estabelecimento de iniciativas de mediação - ambas reforçadas no currículo dos Cursos e Estágios do CCOPAB. Há, portanto, uma conformação às normas de intervenção desenvolvidas pelas Naçóes Unidas, mas, ao mesmo tempo, o estabelecimento de novas regras de construçâo da paz no terreno acumuladas ao longo dos treze anos da MINUSTAH. Há dessa forma uma co-constituição importante entre agente e estrutura, por meio da qual o CCOPAB vem desempenhando um papel na formulação de novas práticas de peacebuilding ainda não sistematizadas pelo DPO. Essa é uma importante forma de contribuição, que vem nâo apenas de concessão de tropas, mas de parâmetros normativos e doutrinários relevantes para o futuro das Operações de Paz das Naçôes Unidas.

Além do CCOPAB, o CIASC, desde a década de 1960, também vem desempenhando sua contribuiçáo no preparo dos peacekeepers brasileiros da Marinha do Brasil (MB). A próxima seção discorre sobre como esse centro de treinamento de uma Força específica do Brasil também colabora não apenas com tropas, mas com questôes normativas e doutrinárias - seguindo, em grande medida, o papel já desempenhado no âmbito do CCOPAB.

\section{A contribuição da Marinha do Brasil para as questões normativas e doutrinárias}

Apesar da existência de um centro integrado de treinamento das Forças Armadas para as Operaçôes de Paz, a MB, que jamais ocupou o co- mando do CCOPAB, por questóes institucionais, vislumbrou a oportunidade de criar o seu próprio centro de capacitação. Tal iniciativa permitiria treinar seu pessoal mobilizado em Operaçóes de Paz, particularmente de caráter naval, além de prepará-los "para a execuçáo de operaçóes de segurança marítima, em apoio ao patrulhamento das águas jurisdicionais brasileiras" (FERREIRA, 2019, p. 213). É digno de nota destacar que a preparaçáo dos Fuzileiros Navais atuantes nas Operações de Paz das Naçôes Unidas e de demais organizaçóes intergovernamentais já era conduzida desde a década de 1960 pelo CIASC, criado ainda em 1955 originalmente com o nome de Centro de Instrução do Corpo de Fuzileiros Navais (CICFN) (CENTRO DE INSTRUÇÃO ALMIRANTE SYLVIO DE CAMARGO, 2019a, s/p). Antes da participação brasileira na MINUSTAH, o CIASC foi responsável pela capacitação dos oficiais do Corpo de Fuzileiros Navais que atuaram na Força Interamericana de Paz, conduzida pela Organização dos Estados Americanos (OEA) em 1965, bem como em Operaçóes de Paz posteriores autorizadas pelo Conselho de Segurança das Naçôes Unidas, tais como: a Força de Proteçâo das Nações Unidas (02/1992), a Missão de Verificação das Naçôes Unidas em Angola III (02/1995), a Missão de Observadores Militares Equador-Peru (03/1995), a Força de Desdobramento Preventivo das Naçóes Unidas na Macedônia (03/1995), a Administração Transitória das Naçôes Unidas para a Eslavônia Oriental, Baranja e Sírmia Ocidental (01/1996), a Administração Transitória das Nações Unidas no Timor-Leste (10/1999), e a Missão das Nações Unidas de Apoio ao Timor-Leste (05/2002) (FERREIRA, 2019a).

Assim como no caso do CCOPAB, o CIASC, alinhado às diretrizes previstas nas Estratégias de Segurança Nacional de 2008, e tendo como pano de fundo o alto engajamento dos Fuzileiros Navais na MINUSTAH (total de 6.500, além de 70 oficiais), 
Figura 2 - Organograma do Centro de Instrução Almirante Sylvio de Camargo

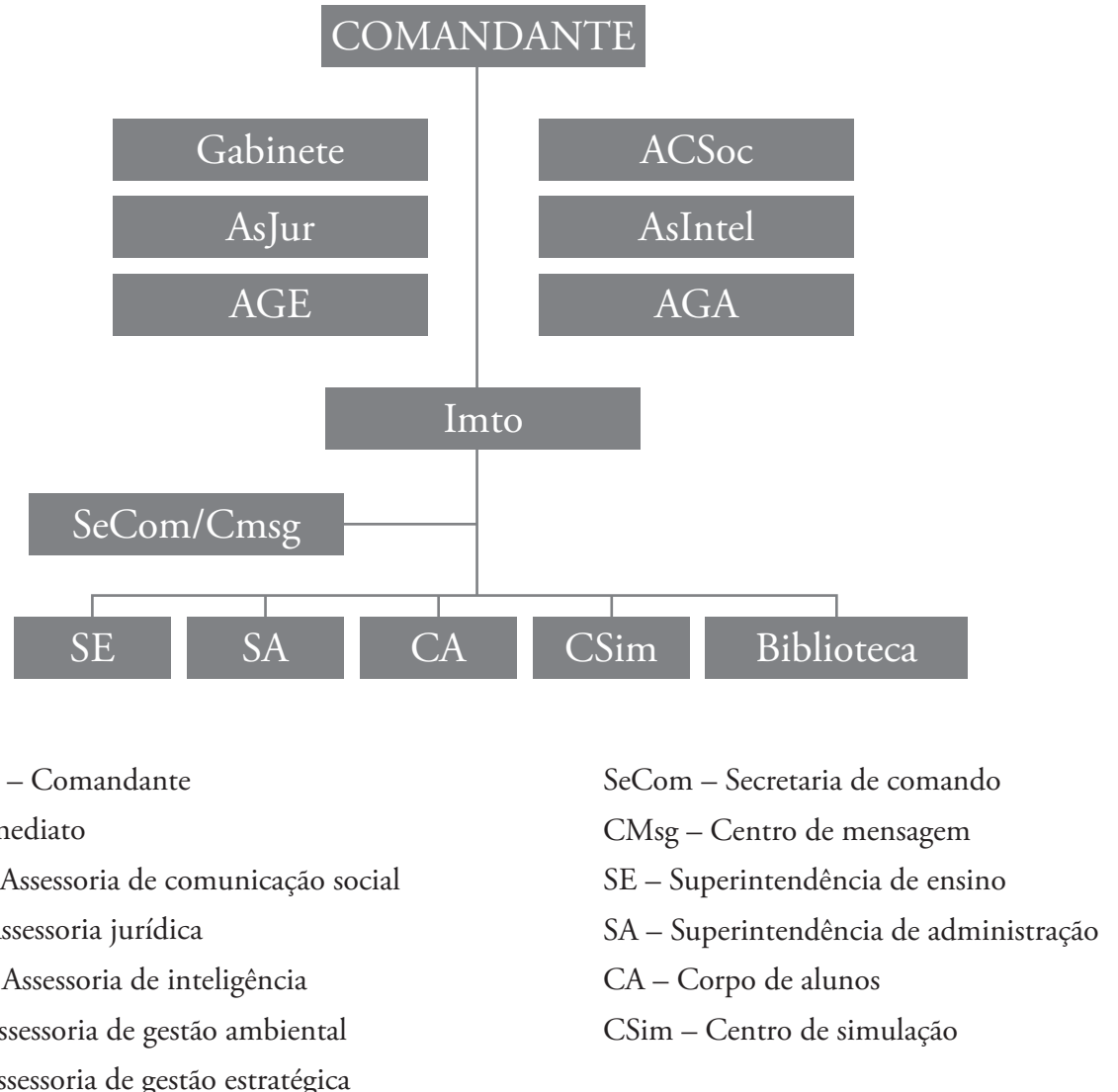

Fonte: CENTRO DE INSTRUÇĀO ALMIRANTE SYLVIO DE CAMARGO, 2019c, s/p.

cria em 2008 a Escola de Operaçóes de Paz do Corpo de Fuzileiros Navais (EOpPaz-CFN) (CENTRO DE INSTRUÇÃO ALMIRANTE SYLVIO DE CAMARGO, 2019b, s/p). A EOpPaz-CFN tinha como objetivo inicial preparar os desdobramentos individuais e coletivos dos integrantes da Marinha para as Operaçôes de Paz das Nações Unidas. De igual modo, cabia à EOpPaz-CFN ser

(...) um órgão capaz de (...) registrar e disseminar os conhecimentos e experiências adquiridos por meio da participação nas Operações de Paz; organizar cursos, estágios e eventos destinados à troca de conhecimentos acerca de tais operaçóes, e representar a Marinha do Brasil, no país e no exterior, em eventos ligados às Operaçóes de Paz" (CENTRO DE INSTRUÇÃO ALMIRANTE SYLVIO DE CAMARGO, 2019b, s/p).
Coube também à EOpPaz-CFN instruir oficiais de forças co-irmãs ${ }^{11}$ a serem enviados em missóes individuais como oficiais de estado maior ou observadores militares (FERREIRA, 2019a). Três anos mais tarde, diante da participação na UNIFIL, a EOpPaz-CFN foi renomeada como a Escola de Operaçóes de

11 Ganha destaque o crescente envolvimento da Aeronáutica nos Cursos e Estágios oferecidos pela Escola de Operaçóes de Paz do Corpo de Fuzileiros Navais. No que concerne à Aeronáutica, os treinamentos desenvolvidos por este braço das Forças Armadas aos seus respectivos oficiais ocorreram tanto no CIASC ainda na década de 1990 quanto no CCO$\mathrm{PAB}$ a partir de sua criaçáo. Adicionalmente, como parte de programas de cooperação bilateral em países como Alemanha, Chile e de nações amigas, os observadores militares e de estado-maior desta Força obtiveram formação e capacitaçáo em tais países de modo a contribuir para o apoio logístico, principalmente em questôes de transporte aéreo nas Operaçóes de Paz das Nações Unidas (FONTOURA, 2005). 
Paz de Caráter Naval (EsOpPazNav) para cumprir aos propósitos específicos daquela missão e de também se "tornar um centro de referência de treinamento para as operaçóes militares em proveito da segurança marítima, no entorno estratégico brasileiro" (CENTRO DE INSTRUÇÃO ALMIRANTE SYLVIO DE CAMARGO, 2019b, s/p). O objetivo da EsOpPazNav é o de preparar "militares da MB, de outras Forças Armadas, Forças Auxiliares e Militares de Naçóes Amigas, assim como civis dos quadros de servidores da própria Força Naval e de outros órgáos e instituiçóes, para as operaçôes de paz" (CENTRO DE INSTRUÇÃO ALMIRANTE SYLVIO DE CAMARGO, 2019b, s/p).

A EsOpPazNav é subordinada à Superintendência de Ensino (SE) ${ }^{12}$ do CIASC "e é composta por uma estrutura permanente, integrada por oficiais e praças da $\mathrm{MB}$ organizados em duas Divisôes: uma Divisão de Operações Marítimas e uma Divisão de Operaçóes Terrestres de Caráter Naval" (CENTRO DE INSTRUÇÃO ALMIRANTE SYLVIO DE CAMARGO, 2019b, s/p). Dirigida atualmente pelo Capitáo de Fragata do Corpo de Fuzileiros Navais Adler Cardoso Ferreira, a EsOpPazNav oferece o Estágio de Preparação para Contingentes em Operaçóes de Paz (E-PrepContOpPaz) ${ }^{13}$, o Estágio de Operaçóes de Paz de Caráter Naval

$12 \mathrm{Na}$ Divisão de Ensino do CIASC são oferecidos os seguintes cursos: Curso de Aperfeiçoamento para Oficiais do Corpo de Fuzileiros Navais; Curso de Carreira para Militares Selecionados do Corpo de Fuzileiros; Curso de Formaçáo para Sargentos Músicos; Curso de Especializaçáo de Guerra Anfíbia; Estágio para Oficiais e Praças; Cursos Especiais, Expeditos e Extraordinários para Oficiais e Praças; Supervisão Pedagógica e Administração Escolar dos Cursos e Estágios Extra-Carreira Conduzidos pelas Organizaçóes Militares Executoras de Cursos (CENTRO DE INSTRUÇÃO ALMIRANTE SYLVIO DE CAMARGO, 2019c, s/p). Para uma relaçâo completa dos cursos oferecidos pelo CIASC, acessar: < https://www.marinha. mil.br/ciasc/conteudo/cursos-ciasc>.

13 O referido Curso é "ministrado aos integrantes de Contingentes, seja para missóes de paz de caráter naval ou terrestre" (FERREIRA, 2019b, s/p). Assim como nos demais Cursos e Estágios, o material utilizado é o Core Pre-deployment Training Materials (CPTM), mas que também é adaptado à algumas particularidades da UNIFIL (FERREIRA, 2019b, s/p).
(E-OpPazNaval) ${ }^{14}$, o Estágio de Preparação para Observadores Militares e Oficiais de Estado-Maior (E-PrepObsMilOfEM) ${ }^{15}$, o Curso Especial de Negociação de Conflitos com Tomada de Reféns (C-EspNeConRef) ${ }^{16}$, o Estágio de Operaçôes de Paz para Mulheres e o Curso Internacional de Operaçóes de Paz de Caráter Naval (UN Maritime Task Force Course) (FERREIRA, 2019b, s/p). Esse último está recentemente em processo de certificação pelo Sistema Integrado de Ensino do Departamento de Operação de Paz (ITS-DPO) (FERREIRA, 2019b, s/p). Nos demais casos não há qualquer certificação do DPO no momento. Para agosto de 2019 está previsto a criação do Estágio de Preparação de Observadores Militares e Oficiais de Estado Maior para Operações de Paz (FERREIRA, 2019b, s/p). A despeito da inexistência de certificação das Naçôes Unidas, todos os referidos Cursos e Estágios tomam como referência os materiais obrigatórios de treinamento e preparação das Naçóes Unidas - evidenciando, desta forma, a internalização dos padróes de segurança internacional previstas pela organização.

14 Estágio "destinado aos comandantes e integrantes de Estado-Maior de Força-Tarefa Marítima, bem como aos Comandantes, Imediatos e chefes de departamento dos navios integrantes de tais Forças-Tarefa" (FERREIRA, 2019b, s/p). O Estágio, que inicialmente estava concentrado na transmissáo de experiências entre os partícipes do passado e futuro da UNIFIL sofrerá uma mudança significativa em função do lançamento do Specialized Training Materials (STM) para a Força Tarefa Marítima das Naçôes Unidas (FERREIRA, 2019b, s/p). Com isto, o Estágio "passará a contar com tal conteúdo, obrigatório, além do conteúdo empírico anterior" (FERREIRA, 2019b, s/p).

15 Estágio "destinado a preparar os oficiais que serão desdobrados em missóes de paz de caráter terrestre, como observadores militares ou oficiais de Estado-Maior" (FERREIRA, 2019b, s/p). Também é baseado no STM das Naçôes Unidas "para observadores militares e para oficiais de Estado-Maior".

16 O objetivo do referido Curso é o de "preparar negociadores no nível tático para ocasióes onde ocorrem a captura de reféns" (FERREIRA, 2019b, s/p). O exercício possibilita fortalecer a segurança de instalaçôes da Marinha do Brasil ou de qualquer outra instituição pública de segurança no Brasil. 
Assim como o CCOPAB, através da DD, a EsOpPazNav vem estabelecendo mecanismos de diálogo e consulta com a sociedade civil e a própria $\mathrm{ONU}$ de modo a investir cada vez mais na aquiescência dos padrões onusianos de treinamento e, aperfeiçoamento de tropas. Exemplo destas iniciativas são a organização do evento internacional alusivo aos 13 anos da participação brasileira na MINUSTAH, realizado nas instalações do CIASC em 2017 e que contou com o então o Subsecretário-Geral do DPO Jean-Pierre Lacroix. Adicionalmente, destaca-se a crescente parceria com o Centro de Informação das Nações Unidas para a organização de cursos conjuntos, como o de gênero e operaçóes de paz. Por fim, cabe notar que a EsOpPazNav vem estreitando laços com o Centro de Treinamento de Operaçóes de Interdição Marítima da Organização do Tratado do Atlântico Norte (OTAN) (FERREIRA, 2019a). Ainda que a OTAN estabeleça alguns princípios divergentes das Naçóes Unidas em alguns aspectos da construção da paz e segurança internacional, essa aproximação planejada pelo CIASC possibilita que o Brasil alcance um patamar de grande ator das questóes de segurança.

A principal contribuição com tropas para as Operaçóes de Paz das Naçóes Unidas por parte do Brasil, ainda que reduzida se comparada com a MINUSTAH, vem justamente da MB: uma fragata e um contingente que varia entre 220 a 280 marinheiros desde 2010 para a UNIFIL (KENKEL, 2018). Dessa forma, o CIASC e, por extensão, a EsOpPazNav vêm contribuindo não apenas para o treinamento das tropas, mas também com questóes normativas e doutrinais a partir da sua experiência no comando da Força Tarefa Marítima (FTM), tradicionalmente ocupada por países membros da OTAN. Tal contribuição se manifesta no intercâmbio de instrutores que difundem melhores práticas no contexto da FTM; na realização de workshops e encontros para compartilhar narrativas e experiências oriundas da MINUSTAH e UNIFIL. Adicionalmente, cabe destacar a crescente participação de oficiais da MB, na figura de seus Comandantes, em encontros da IAPTC e em cargos de destaque no DPO. De modo não exaustivo, é necessário pontuar a associação do CIASC ao Peace Operations Training Institute (POTI $)^{17}$ - plataforma de ensino e treinamento sobre Operaçóes de Paz baseada em Washington, nos Estados Unidos da América. Promovendo o intercâmbio e especialização de seus instrutores, o CIASC busca inserir o Brasil no rol de Estados parceiros da referida instituição para a discussão de questóes normativas, doutrinárias e operacionais.

A UNIFIL tem servido ao propósito, assim como a MINUSTAH foi para o CCOPAB, de plataforma de projeção de expertise brasileira no exterior. Ainda que nenhum projeto de cooperação externa esteja ocorrendo no presente momento, a MB, na esteira da recente mencionada portaria do MD que estabelece as normas para o emprego de Equipes Móveis de Treinamento do Centro Conjunto de Operaçóes de Paz do Brasil como mecanismos de cooperação multilaterais, pretende desenvolver a mesma iniciativa entre nações amigas a convite delas. Cabe destacar, de igual modo, o papel dos Comandantes do CIASC, que, ao longo dos últimos anos, também estão vislumbrando oportunidades para projetar o Brasil, através das Forças Navais, como relevante ator no campo da segurança internacional e regional.

\section{Considerações finais}

Tanto o CCOPAB quanto o CIASC representam instituiçóes de treinamento que se ade-

17 O POTI é uma organização não governamental e independente governada por um Conselho Diretor que tem como principal objetivo oferecer cursos online/à distância em temas de alívio humanitário, suporte à paz, operaçôes de segurança (MARCONDES; SÍMAN, OLIVEIRA, 2019, p. 206). O POTI trabalha em parceria com diversas organizaçóes regionais para a disseminaçáo de conhecimento sobre a temática de Operaçôes de Paz, além de contar com Estados que contribuem na produção e confecção dos materiais. Para mais informaçóes, acessar: https://www.peaceopstraining.org/ 
quaram progressivamente às normas e padróes de intervenção das Naçôes Unidas. Ao mesmo tempo em que ocorre a adesão à tais princípios, ambas buscam, como forma de ocupar um espaço tradicionalmente habitado por Estados do Norte Global, projetar o Brasil como relevante contribuinte às causas da paz e segurança internacional a partir de suas próprias experiências. No contexto de asfixia econômica e política, onde não há uma diretriz ou previsão clara do atual governo quanto às Operações de Paz, o caminho encontrado pelos centros de treinamento em questão vem sendo o de manter a memória institucional e prática através de oportunidades vislumbradas no campo da paz e segurança internacional. Dependente da habilidade e esforços pontuais, o Brasil, aos poucos, vem tentando diferenciar o seu padrão de contribuição paras as Naçóes Unidas: de doador de tropas para um Estado que contribui para as causas da paz e segurança internacional do ponto de vista normativo e doutrinário.

Outros exemplos que fogem ao escopo de análise da presente pesquisa e que corrobora com os pontos desenvolvido até o momento são, em primeiro lugar, a participação do ex-Force Commander da MINUSTAH, General Floriano Peixoto Vieira Neto, no Painel Independente de Alto Nível para as Operaçóes de Paz. Ademais, recentemente, a ganha projeção a publicação do relatório do ex-Force Commander da MINUSTAH e MONUSCO, General Carlos Alberto dos Santos Cruz intitulado "Improving Security of United $\mathrm{Na}$ tions Peacekeepers: We need to change the way we are doing business". Ainda que ambos os generais não representem a posição do Estado brasileiro, suas vozes ecoam como reflexo da experiência que o Brasil vem acumulando ao longo dos últimos anos do presente século, contribuindo para os debates relacionados à construção de uma paz sustentável no médio e longo prazo. Tanto o CCOPAB e o CIASC estấo se comprometendo com os pontos elencados nestes documentos, capacitando tropas e estimulando debates e reflexóes internas e externas sobre a possibilidade de um peacebuilding alternativo ao modelo vigente da paz liberal.

\section{Agradecimentos}

A pesquisa apresentada aqui é parte do envolvimento do autor na Rede Brasileira de Pesquisa Sobre Operações de Paz (REBRAPAZ). O autor gostaria de agradecer o apoio do CCOPAB e CIASC na coleta de informaçóes e reprodução de dados.

\section{Referências}

BRASIL. Ministério da Defesa. Instrução Normativa no $2 /$ EMCFA/MD, de 17 de junho de 2019. Diário Oficial da União, Brasília, ed. 117, seçấo 1, p. 19, 19 jun. 2019. Disponível em: <http://www.in.gov.br/web/dou///instrucao-normativa-n-2/emcfa/md-de-17-de-junho-de-2019-164322333>. Acesso em: 02 jul. 2019.

CENTRO CONJUNTO DE OPERAÇÓES DE PAZ DO BRASIL. Sobre o CCOPAB: Organograma. Rio de Janeiro, 2019a. Disponível em: <http://www.ccopab.eb.mil.br/pt/sobre-o-ccopab>. Acesso em: 19 de jun. de 2019.

CENTRO CONJUNTO DE OPERAÇÓES DE PAZ DO BRASIL. Sobre o CCOPAB: Subordinação. Rio de Janeiro, 2019b. Disponível em: <http://www.ccopab.eb.mil.br/pt/sobre-o-ccopab>. Acesso em: 19 de jun. de 2019.

CENTRO CONJUNTO DE OPERAÇÓES DE PAZ DO BRASIL Cursos e Estágios. Rio de Janeiro, 2019c. Disponível em: <http://www.ccopab.eb.mil.br/pt/cursos-e-estagios>. Acesso em: 19 de jun. de 2019.

CENTRO CONJUNTO DE OPERAÇÓES DE PAZ DO BRASIL. Documento Interno Produzido pela Divisáo de Doutrina. Rio de Janeiro, 2018.

CENTRO DE INSTRUÇÃO ALMIRANTE SYLVIO DE CAMARGO. Histórico do CIASC. Rio de Janeiro, 2019a. Disponível em: <https://www.marinha.mil.br/ciasc/conteudo/ historico>. Acesso em: 19 de jun. de 2019.

CENTRO DE INSTRUÇÃO ALMIRANTE SYLVIO DE CAMARGO. A Escola de Operaçóes de Paz de Caráter Naval. Rio de Janeiro, 2019b. Disponível em: <https://www.marinha.mil. br/ciasc/conteudo/esoppaznav>. Acesso em: 19 de jun. de 2019. CENTRO DE INSTRUÇÃO ALMIRANTE SYLVIO DE CAMARGO. Estrutura da Escola de Operaçóes de Paz de 
Caráter Naval. Rio de Janeiro, 2019c. Disponível em: <https://www.marinha.mil.br/ciasc/conteudo/estrutura-esoppaznav>. Acesso em: 19 de jun. de 2019.

FERREIRA, Adler Cardoso. A Escola de Operaçóes de Paz de Caráter Naval. In: MARINHA DO BRASIL. 13 Anos do Brasil na MINUSTAH: liçôes aprendidas e novas perspectivas. Rio de Janeiro: Marinha do Brasil, p. 213-224, 2019a. No Prelo.

FERREIRA, Adler Cardoso. Entrevista concedida a Ricardo Oliveira dos Santos. Rio de Janeiro, 18 mai. 2019b.

FONTOURA, Paulo Roberto Campos Tarrisse Da. O Brasil e as Operaçóes de Manutençáo da Paz das Naçóes Unidas. Brasília: Editora Fundação Alexandre de Gusmão, 2005.

GOVERNO FEDERAL DO BRASIL. Política Nacional de Defesa e Estratégia Nacional de Defesa. Ministério da Defesa: Brasília, 2012. Disponível em: <http://www.defesa.gov.br/ arquivos/estado_e_defesa/END-PND_Optimized.pdf $>$. Acesso em: 19 de jun. de 2019.

HAMANN, Eduarda. A Força de Uma Trajetória. Rio de Janeiro: Instituto Igarapé, 2015.

KENKEL, Kai Michael. Providing for Peacekeeping. Peacekeeping Contributor Profile: Brazil. Providing For Peacekeeping,
2018. Disponível em: <http://www.providingforpeacekeeping. org/2014/04/03/contributor-profile-brazil/>. Acesso em: 19 de jun. de 2019.

KENKEL, Kai Michael. Brazil. In: BELLAMY, Alex J. \& WILLIAMS, Paul D. (Eds.). Providing Peacekeepers: The Politics, Challenges, \& Future of United Nations Contributors. Oxford: Oxford University Press, p. 335-354, 2013.

MARCONDES, Danilo; SÍMAN, Maíra; OLIVEIRA, Ricardo. South-South Cooperation and Training for Peacekeeping Participation: Expertise and Status in Brazil's Involvement in Africa and Latin America. Journal of International Peacekeeping, v. 21, n. 3-4, p. 197-223, 2019.

TEIXEIRA, Carlos Augusto Ramires. O Centro Conjunto de Operaçōes de Paz do Brasil: história e perspectivas pós-MINUSTAH. In: HAMANN, Eduarda Passarelli; TEIXEIRA, Carlos Augusto Ramires (Orgs.). A participaçáo do Brasil na MINUSTAH (2004-2017): percepçôes, liçôes e práticas relevantes para futuras missões. Rio de Janeiro: Instituto Igarapé, p. 25-35, 2017. UNITED NATIONS. General Assembly Resolution 44/49. New York, 1989. Disponível em: <https://undocs.org/en/A/ RES/44/49>. Acesso em: 24 de jun. de 2019. 